\title{
Dynamic Capabilities as Determinants of Supply Chain Performance in Small to Medium Enterprises
} in Gauteng Province

\author{
Phathutshedzo David Lavhelani, OsayuwamenOmoruyi, Elizabeth Chinomona* \\ Department of Logistics,Vaal University of Technology, South Africa \\ chakubvaelizabeth@gmail.com
}

\begin{abstract}
The objective of the study is to investigate dynamic capabilities, service quality and relationship longevity as determinates of supply chain performance in small to medium enterprises in Gauteng province by focusing on small and medium enterprises in the Vaal region. The study will contribute to the body of knowledge by addressing dynamic capabilities as determinates of supply chain performance in small to medium enterprises. The study employs a quantitative method of data collection. Permission was sought from SME owners. Once permission was granted, the questionnaires were sent out to SME owners. A total 425 participates were chosen to participate in this study. The researcher used the Statistical Package for the Social Sciences (SPSS 24.0) and Analysis of Moment Structures (AMOS 24.0) to analyse the data. Sample data from SME owners/managersof Vaal region was collected for the final data analysis of this project. The sample data were analysed by performing a confirmatory factor analysis (CFA) and structural equation modelling (SEM). The principal finding of this study reveals that dynamic capabilities, relationship longevity and service quality have an impact on supply chain performance. The conclusions and implications of the research findings are provided and recommendations are suggested.
\end{abstract}

Keywords: Dynamic capabilities, Supply chain longevity, Supply chain performance, Dynamic capabilities theory

\section{Introduction}

The importance of the study is to investigate the influence dynamic capabilities, service quality and relationship longevity on supply chain performance. SMEs, by nature are flexible and adaptable organisations that can respond quickly to market changes (Hudson \& Smith, 2008). In South-Africa, SMEs are widely considered to be heterogeneous groups of businesses ranging from a single artisan worker in a village market to a more sophisticated firm selling in the market (Christensen \& Poulfet, 2010). However, in order for them to survive, SMEs have to adopt supply chain management practices (Bayraktar, Gunasekaran, Koh, Tatoglu, Demirbag \& Zaim, 2010). Supply chain management is the flow of materials, information and service from the original supplier until the final stage (Branch, 2009). It may also be defined as the material and informational interchanges in the logistical process, stretching from acquisition of raw materials to the delivery of finished products to the end users (Vitasek, 2008). The adoption of supply chain management is important in that it enhances the productivity of shorter life cycles products, encourages stronger competitiveness amongst businesses and leads to levels of customer satisfaction in the vast and uneven global market (Manzouri, Rahman, Arshad \& Ismail, 2010). Within SMEs, supply chain management practices are renowned for increasing effectiveness and efficiency in operations (Trkman \& McCormack, 2010). This makes the adoption of supply chain management practices an important priority for SMEs. Another emergent issue that is important to supply chain management in SMEs of today is the subject of dynamic capabilities (DC). Augier and Teece (2008) have described DC as the tool that is concerned with how the SMEs create new knowledge, distribute it internally, plant it into new services or products and launch them into the market. DC permit an organisation to create new combinations of ordinary capabilities (Pavlou \& Eisawy, 2011). A brief example is when the product development processes or routines are higher-order DC that are employed in order to reconfigure the types of products as a firm manufactures or produces the service it offers (Danneels, 2008). In the context of SMEs, DC explore how changes in the world are likely to result in changes in the SMEs and improve their capabilities (Augier \& Teece, 2008). This means that introducing DC will give SMEs opportunities to acquire new skills and improve the existing ones (Terziovski, 2010).

Problem Statement: SMEs across the world and in South Africa in particular continuously face numerous challenges that inhibit entrepreneurial growth (Charles, 2009). Apart from SME funding and access to finance, 
SMEs in South Africa also suffer from poor management skills, which are a result of lack of adequate training and education, resulting in high rates of business failure (Gunasekaran \& Kobu, 2007). Despite various support programmes implemented by the Government, SMEs are failing to achieve the Government's desired performance and growth rate of 5 percent per annum (Olawale \& Garwe, 2010). This failure of SMEs to reach the desired performance levels has motivated this study to examine other areas of SMEs management and supply chain that could potentially stimulate higher performance in SME supply chains. This study aims to provide a deeper understanding on the key factors that can improve the performance of supply chains in which SMEs operate in South Africa by exploring the matter from the perspective of critical supply chain management practices such as dynamic capabilities (DC), relationship longevity (RL) and service quality (SQ). This potentially may yield information that is useful in the prevention of continued SME business failure in South Africa.

Given the challenges of maintaining competitive edge by SMEs, various research endeavours (Adams, Khoja \& Kauffman, 2012; Chinomona \& Chinomona, 2013; Mafini \& Omoruyi, 2013) have been made, which are directed to the implementation of supply chain management activities to enhance SME supply chain performance (SCP). This fact notwithstanding, there is scant evidence of previous studies that attempted to test the conceptual framework put forward in this study in the South African SME economic sector. Hence, the previous literature has very little content regarding the impact of the DC on SCP in South African SMEs. The relationship between DC, RL and SQ on SCP is established, this study exploits the gaps that exist currently in this potentially interesting research area. This study will clarify the importance of DC, RL and SQ in SMEs and determine their importance on SCP. The study will also provide information on how DC can be manipulated in order to stimulate RL between buyers and suppliers as well as superior SQ within SMEs. This provides further clarity on the interplay between these constructs from the perspective of an emerging economy in an African context.

\section{Literature Review}

Dynamic Capabilities View Theory (DVC): The theoretical background informing this study draws from a dynamic capability view (DCV) theory which, in essence, is an extension of the resource-based view of the firm, which highlights how the firm develops and sustains competitive advantage and superior profitability (Cavusgil, Seggie \& Talay, 2007). As an extension, the DCV stresses the key role of management to appropriately adjust, integrate and reshape organisational skills and resources as well as internal and external functional competences (Borch \& Madsen, 2007). Capabilities are said to be dynamic when they provide organisations with the ability to implement different strategies to adopt to varying market conditions (Barreto, 2010). A firm's DC are characterised by its capacities to sense and shape opportunities and threats, grab opportunities and maintain competitiveness through enhancing, combining, protecting and when necessary, reconfiguring the business enterprise's intangible and tangible assets (Teece, 2007). DC also includes the ability to identify the need for change, to formulate a response and to implement appropriate measures, which is necessary for the success of the enterprise (Helfat, 2008). The DCV theory contends that in a business environment where the competitive landscape is continuously shifting, a firm's DCs become the source of sustained competitive advantage (Morgan, Neil, Vorhies, Douglas, Charlotte, 2009). As such, in a business environment where the competitive landscape is constantly shifting, supply chain managers need to utilise capabilities offered by the use of electronic toll collection systems and service delivery in order to sustain RL in supply chains and to make suppliers perform at a higher level (Pavlou \& ElSawy, 2011). Therefore, DCs represent the capacity of an organisation to purposefully create, extend or modify its resource base and thus represents a dynamic extension of RBV theory (Helfat \& Peteraf, 2009).

Service quality: Service quality (SQ) can be defined as a performance that one party can offer to another that is essentially intangible and does not result in the ownership of anything (Kotler \& Keller, 2010). SQ can also be defined as the overall assessment of service by customers (Eshghi, Roy \& Ganguli, 2008). In any economy, SMEs tend to be the backbone to general business health (Supyuenyong, Islam \& Kulkarni, 2009). This being the case, SMEs that intend to remain relevant, competitive and constant must persevere towards delivering the best high quality service to customers (Ladhari, 2008). Factors influencing SQ include organisational 
culture, management style, job satisfaction, resource availability, skills and expertise, performance monitoring and feedback, organisational communication, employee job fit and quality of teamwork (Ihtiyar \& Ahmad, 2012). Some of the benefits that SMEs stand to enjoy by emphasising SQ include getting a competitive edge, high customer satisfaction, excellence in design, all of which lead to high overall SME performance (Ghylin, Green, Drury \& Chen, 2008). Since effective SQ results in a wide spectrum of benefits to the SMEs, it may be stated that SQ determines the long-term survival of such enterprises.

Relationship longevity: Relationship longevity (RL) can be defined as the way in which the firms relate with suppliers. RL with the supplier can also be referred to as the value and inclination of both parties towards the relationship, as they consider the required levels of commitment, advantages, limitations and most buyers and sellers recognise the need for teamwork between buyers and suppliers as the best way to reduce costs and ensure quality, delivery, time and other measures of performance. The relationship is two sided, as both parties have the power to shape their future direction (Lai, Wong \& Cheng, 2010). According to some authors (Prajogo \& Olhager, 2012), given that firms such as SME firms are getting more focused on their core competences, there are three key aspects of long-term relationships with suppliers. First, the trend is to build a long-term relationship with suppliers rather than shorter contracts. Secondly, SMEs now tend to use fewer suppliers over longer periods rather keeping a large base of suppliers, which allows them to change suppliers at almost every contract. Thirdly, the relationship with suppliers has been enhanced into strategic levels where the suppliers are now considered as integral parts of the firm operations. Relationships with suppliers are likely to improve once these three parameters are satisfied. Nurturing long-lasting relationships requires communication effectiveness, cooperation and transparency, which constitute key factors for trust development between buyers and suppliers (Paiva, Phonlor \& D'avila, 2008). In turn, once such mutually reciprocal relationships are established, they lead to improvements in such areas as process integration, collaboration, information sharing and usually it leads to high levels of client's satisfaction (Cousins, Lawson \& Squire, 2008). Furthermore, improvements in costs, quality, delivery and flexibility and operational performance may be realised when the supplier is committed with the buyer (Chinomona, 2013). This makes it important that volatile organisations such as SMEs embrace the building of long-lasting relationships with their suppliers, in order for them to enjoy the benefits emanating from such practices.

Supply chain performance: According to Olugu and Wong (2009), supply chain performance (SCP) may be perceived as the feedback on operations, which are geared towards customer satisfaction and strategic decisions and objectives within supply chains. Shephered and Gunter (2011) define SCP as the process of quantifying the effectiveness and efficiency of action within supply chains. SCP can also be regarded as a tool for managing competitive advantage (Deshpande, 2012). It creates an understanding of supply chain's processes, guides collaboration efforts and optimises supply chain excellence (Faweet, Ellram \& Ogden, 2007). As indicated by Gunasekaran and Kobu (2007), SCP is essential to measure the right things at the right time in a supply chain so that timely action can be taken. With reference to SMEs, the survival and growth of small and medium companies can be difficult in current competitive business environments and the global marketplace since customers are demanding to have better and cheaper products, higher SQ levels, more product varieties and faster product and service delivery (Chin, Hamid, Rasli \& Baharun, 2012). In addition, the changes of business models such as lower production cost, delivery of ever-increasing customer value, flexibility with superior service and the unescapable impact of information and communication technology are increasingly creating enormous challenges for SMEs to survive (Thakkar, Kanda \& Deshmukh, 2009). Fortunately, these developments can be mitigated through improvements in SCP, which means that the higher the SCP, the greater the possibility of superior performance within SMEs (Chin et al., 2012). Therefore, SMEs have the prerogative of monitoring and controlling their operations on a daily basis in order to get the performance desired from their supply chain.

Research Model: Based on the literature reviewed, the following research model has been developed. Hypotheses relationships between variables will be developed thereafter. In the conceptualised research model, DC form the predictor variable, which feeds into SQ, RL that are the mediators. SCP is the outcome variable. 


\section{Hypotheses statements}

Based on the conceptual model above, the following hypotheses statements have been proposed.

H1: There is a positive relationship between dynamic capabilities and service quality amongst SMEs in the province of Gauteng;

H2: There is a positive relationship between dynamic capabilities and relationship longevity amongst SMEs in the province of Gauteng;

H3: There is a positive relationship between dynamic capabilities and supply chain performance amongst SMEs in the province of Gauteng;

H4: There is a positive relationship between service quality and supply chain performance amongst SMEs in the province of Gauteng;

H5: There is a positive relationship between relationship longevity and supply chain performance amongst SMEs in the province of Gauteng.

Figure 1: Research Model

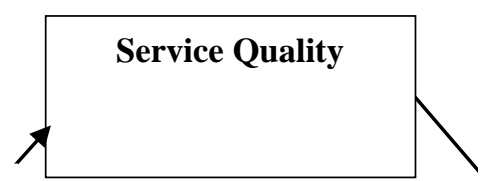

H1

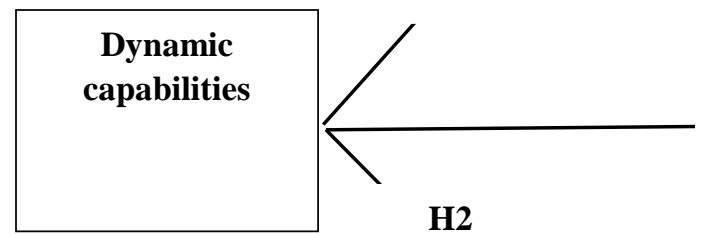

H4

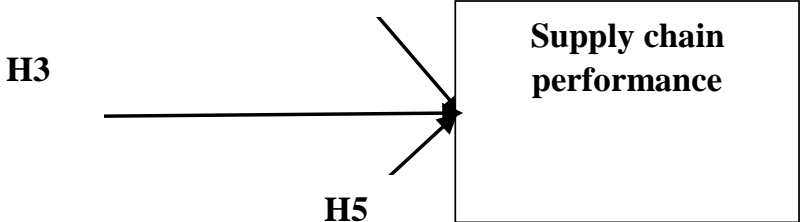

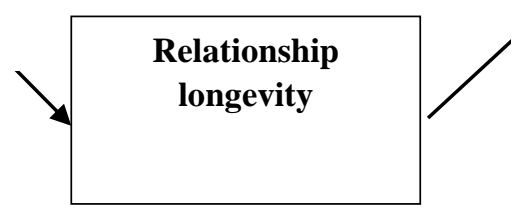

\section{Method}

A non-probability convenience sampling method was chosen for the purpose of this study since the characteristics of this method have particular appeal to financial and time constraints. Convenience sampling allows a large number of respondents to be interviewed within a relatively short period of time. Moreover, the convenience sampling procedure was used in selecting the participants because of the ease of the researcher's access to these cohorts of business owners and their willingness to participate in the study. The sample size was set at 425 . Of all the self- administered questionnaires distributed, only 288 were usable for final analysis. 137 were either not returned or incomplete and could not be used because some of the sections were completed partially. This yielded a valid response rate of 68 percent. This response rate was acceptable because it is above the 50 percent minimum threshold suggested by Kidder (1981). Use of self-administered questionnaire is employed because of its cost effectiveness and easy to administer. The method also ensured a greater possibility of anonymity and greater convenience for the respondents since they could complete the questionnaire at their own time and pace.

\section{Data Analysis and Results}

Reliability Test: In this study, three tests were conducted, namely Cronbach's alpha, CR and AVE, in order to assess reliability and validity. The Cronbach alpha test measures reliability, while CR and AVE tests seek to confirm and validate the measurement instruments. 
Cronbach's alpha test: From the results provided in Table 1, the Cronbach alpha for each research construct ranges from 0.757 to 0.804 and as these are above the required threshold of 0.6 , which is recommended by Nunally and Berstein (1994). Furthermore, the item to total values range from 0.660 to 0.891 . The Cronbach alpha results are indicated in Table 1 and validate the reliability of measures used for the current study. A Composite reliability (CR) index that is greater than 0.6 signifies sufficient internal consistency of the construct. In this regard, the results of CR that range from 0.757 to 0.805 in Table 1 confirms the existence of internal reliability for all constructs. A good representation of the latent construct by the item is identified when the variance extracted estimate is above 0.5 (Sarstedt, Ringle, Smith, Reams \& Hair,2014). Therefore, the results of average variance extracted (AVE) that range from 0.533 to 0.717 in Table 1 authenticate good representation of the latent construct by the items.

Discriminant validity: To check if there is discriminant validity is to assess if the correlation between the researches constructs is less than 1.0 as recommended by Chinomona (2011:110). As indicated in Table 2, the inter-correlation values for all paired latent variables are less than 1.0 hence confirming the existence of discriminant validity.

Table 1: Accuracy analysis statistics

\begin{tabular}{|c|c|c|c|c|c|c|c|c|}
\hline \multicolumn{2}{|c|}{$\begin{array}{l}\text { Research } \\
\text { constructs }\end{array}$} & \multicolumn{4}{|c|}{ Descriptive statistics Cronbach's test } & \multirow[t]{2}{*}{ C.R. } & \multirow[t]{2}{*}{ AVE } & $\begin{array}{l}\text { Factor } \\
\text { loading }\end{array}$ \\
\hline & DC1 & \multirow{4}{*}{3.79} & \multirow{4}{*}{0.989} & 0.771 & \multirow{4}{*}{0.766} & & & 0.822 \\
\hline 品 & DC2 & & & 0.845 & & \multirow{3}{*}{0.767} & \multirow{3}{*}{0.713} & 0.863 \\
\hline 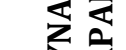 & DC3 & & & 0.855 & & & & 0.850 \\
\hline ไิ త & DC4 & & & 0.834 & & & & 0.844 \\
\hline \multirow{9}{*}{ 空 } & SQ1 & \multirow{5}{*}{3.87} & \multirow{4}{*}{1.025} & 0.797 & \multirow{4}{*}{0.760} & \multirow{4}{*}{0.759} & \multirow{4}{*}{0.533} & 0.800 \\
\hline & SQ2 & & & 0.660 & & & & 0.648 \\
\hline & SQ3 & & & 0.629 & & & & 0.681 \\
\hline & SQ4 & & & 0.656 & & & & 0.683 \\
\hline & RL1 & & & 0.740 & & & & 0.791 \\
\hline & RL2 & \multirow{5}{*}{4.00} & \multirow{5}{*}{0.907} & 0.849 & \multirow{4}{*}{0.757} & \multirow{4}{*}{0.757} & \multirow{4}{*}{0.717} & 0.842 \\
\hline & RL3 & & & 0.859 & & & & 0.857 \\
\hline & $\begin{array}{l}\text { RL4 } \\
\text { RL5 }\end{array}$ & & & $\begin{array}{l}0.8 \angle 5 \\
0.844\end{array}$ & & & & 0.857 \\
\hline & RL6 & & & 0.810 & & & & 0.854 \\
\hline \multirow{8}{*}{ 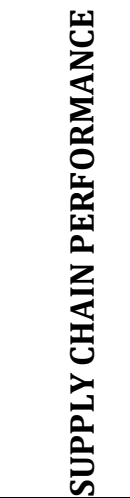 } & SCP1 & & & 0.880 & \multirow{8}{*}{0.804} & \multirow{8}{*}{0.805} & \multirow{8}{*}{0.555} & 0.719 \\
\hline & SCP2 & \multirow{7}{*}{3.96} & \multirow{7}{*}{0.949} & 0.853 & & & & 0.523 \\
\hline & SCP3 & & & 0.667 & & & & 0.823 \\
\hline & SCP4 & & & 0.725 & & & & 0.623 \\
\hline & SCP5 & & & 0.834 & & & & 0.861 \\
\hline & SCP6 & & & 0.612 & & & & 0.719 \\
\hline & SCP7 & & & 0.891 & & & & 0.753 \\
\hline & SCP8 & & & 0.656 & & & & 0.812 \\
\hline
\end{tabular}


Table 2: Correlations: dynamic capability, service quality, relationship longevity and supply chain performance

\begin{tabular}{lllll}
\hline RESEARCH CONSTRUCTS & DC & SQ & RL & SCP \\
\hline DYNAMIC CAPABILITIES & 1 & & & \\
SERVICE QUALITY & $0.604^{* *}$ & 1 & & \\
RELATIONSHIP LONGEVITY & $0.608^{* *}$ & $0.565^{* *}$ & 1 & \\
SUPPLY CHAIN PERFORMANCE & $0.621^{* *}$ & $0.468^{* *}$ & $0.668^{* *}$ & 1 \\
\hline
\end{tabular}

Table 3: Confirmatory factor analysis model fit results

\begin{tabular}{llll}
\hline CFA indicator & Acceptance level & Default model value & Decision \\
\hline Chi-square & $<3.00$ & 2.341 & Accepted level \\
GFI & $>0.900$ & 0.900 & Accepted level \\
CFI & $>0.900$ & 0.962 & Accepted level \\
RFI & $>0.900$ & 0.926 & Accepted level \\
IFI & $>0.900$ & 0.962 & Accepted level \\
TLI & $>0.900$ & 0.955 & Accepted level \\
NFI & $>0.900$ & 0.938 & Accepted level \\
RMSEA & $<0.08$ & 0.067 & Accepted level \\
\hline
\end{tabular}

However, since the acceptable CFA measurement model fit was secured, the study proceeded to the next stages of checking the SEM model fit and testing of hypotheses. Table 4 reports the structural equation model fit results. The results show the acceptable goodness-of-fit of the model. The acceptable models are indicated by the chi-square value (CMIN/DF) of 2.318 less than the recommended threshold level of $<0.3$, RMSEA value of $0.064, \mathrm{GFI}, \mathrm{CFI}, \mathrm{RFI}, \mathrm{IFI}, \mathrm{TLI}$ and NFI with the values of $0.903,0.765,0.730,0.965,0.959$ and 0.940 respectively. These results are within the recommended level of greater than 0.900 (Malhotra, 2010:19).

Table 4: Structural equation model fit results

\begin{tabular}{llll}
\hline CFA indicator & Acceptance level & Default model value & Decision \\
\hline Chi-square & $<3.00$ & 2.318 & Accepted level \\
GFI & $>0.900$ & 0.903 & Accepted level \\
CFI & $>0.900$ & 0.765 & Not accepted level \\
RFI & $>0.900$ & 0.730 & Not accepted level \\
IFI & $>0.900$ & 0.965 & Accepted level \\
TLI & $>0.900$ & 0.959 & Accepted level \\
NFI & $>0.900$ & 0.940 & Accepted level \\
RMSEA & $<0.08$ & 0.064 & Accepted level \\
\hline
\end{tabular}

The statistics for the model fit provided were above the recommended thresholds, indicating that the proposed conceptual framework converged reasonably well with the underlying empirical data structure.

Discussion of Empirical Findings: Table indicates the proposed hypotheses, factor loadings, $\mathrm{p}$ values and whether a hypothesis is rejected or supported. The literature asserts that $p<0.05, p<0.01$ and $p<0.001$ are indicators of relationship significance and that positive factor loadings indicate strong relationships among latent variables (Chinomona, Lin, Wang \& Cheng, 2010:191). 
Table 5: Hypotheses results

\begin{tabular}{lllll}
\hline $\begin{array}{l}\text { Construct } \\
\text { Measured }\end{array}$ & Hypothesis & $\begin{array}{l}\text { Path } \\
\text { Coefficient }\end{array}$ & P-value & $\begin{array}{c}\text { Rejected/ } \\
\text { Supported }\end{array}$ \\
\hline $\begin{array}{l}\text { Dynamic capabilities } \\
\rightarrow \text { Service quality }\end{array}$ & $\mathrm{H} 1$ & 0.419 & $* * *$ & Supported \\
$\begin{array}{l}\text { Dynamic capabilities } \\
\rightarrow \text { Relationship longevity }\end{array}$ & $\mathrm{H} 2$ & 0.813 & $* * *$ & Supported \\
$\begin{array}{l}\text { Service quality } \\
\rightarrow \text { Supply chain performance }\end{array}$ & $\mathrm{H} 3$ & 0.901 & $* * *$ & Supported \\
$\begin{array}{l}\text { Relationship longevity } \\
\rightarrow \text { Supply chain performance }\end{array}$ & $\mathrm{H} 4$ & 0.421 & $* * *$ & Supported \\
$\begin{array}{l}\text { Dynamic capabilities } \\
\rightarrow \text { Supply chain performance }\end{array}$ & $\mathrm{H} 5$ & 0.903 & $* * *$ & Supported \\
\hline$*$ Significancel lever & & &
\end{tabular}

* Significance level $\mathrm{p}<0.05 ;{ }^{* *}$ significance level $\mathrm{p}<0.01 ;{ }^{* * *}$ significance level $\mathrm{p}<0.001$

Hypothesis testing 1: Results found following the test of Hypothesis 1, confirmed the relationship between DC and SQ. A coefficient of 0.419 was realised after testing Hypothesis 1 . This means that DCs have a positive influence on service quality. Furthermore, the results indicate that the relationship between DC and SQ is significant at $\mathrm{P}<001$. From the results, it can be understood that when new skills are being found, SMEs can be able to provide quality services in order to fulfil customer's demands. However, it can be noticed that the path coefficient between dynamic capability and SQ is quiet low compared to the path coefficient between DC and RL. This suggests that SMEs might be lacking the capability to improve more on their SQ rendered. As such, SMEs overall assessment of service by customers might be poor, thereby hindering the long-term survival of SMEs (Eshghi, Roy \&Ganguli, 2008). SMEs, therefore, should improve their resource integration capabilities and learning capabilities in order to improve their SQ.

Hypothesis testing 2: The results obtained after the testing of Hypothesis 2 validated the presence of a relationship between DC and RL. Following the test of Hypothesis 2, a coefficient of 0.813 was exhibited. This means that DCs have a positive and relatively strong influence on RL. Furthermore, the relationship between DC and RL is significant. These results confirm the relationship as hypothesised. From the results, it can be judged that when there are new skills and new opportunities, SMEs are more likely to go into long-term relationships with their suppliers. This is because dynamic capability sustains competitive advantages and enhances superior profitability. With this, the value of both parties towards the relationship is increased thereby resulting in RL (Fink, Edelman \&Hatten, 2007). Nurturing long-lasting relationships, which require communication effectiveness, cooperation and transparency constitutes key factors for trust development between buyers and suppliers (Paiva, Phonlor \& D'avila, 2008).

Hypothesis testing 3: The relationship between SQ and SCP was confirmed by the results obtained. A coefficient of 0.901 was realised after testing Hypothesis 3. This means that SQ has a positive and strong influence on SCP. More so, the results revealed that the relationship between SQ and SCP is significant at $\mathrm{p}<001$. The results validate the relationship as hypothesised. With this, it can be accepted that SQ can increase the level of SMEs SCP over time. From the observation, SMEs SCP is influenced by services quality with an explanatory power of (0.901) more than as in the case of RL and SCP. This may be because the better the service offered the more the supply chain will perform well, which may further influence SMEs decision to consider RL. In any economy, SMEs tend to be the backbone to general business health (Supyuenyong, Islam \& Kulkarni, 2009). This being the case, SMEs that intend to remain relevant and competitive must constantly persevere towards delivering the best and highest quality service to customers (Ladhari, 2008).

Hypothesis testing 4: The results obtained following the test of Hypothesis 4 verified that there is a relationship between RL and SCP. After testing Hypothesis 4, a coefficient of 0.421 was exhibited. This means that RL has a positive and strong relationship with SCP. Results revealed that the relationship between RL and SCP is significant at $p<001$. The results substantiate the relationship as hypothesised. From the results, it can be accepted that when firms develop relationships that are long-term orientated, they are likely to 
improve or increase the performance of their supply chain. Therefore, when SMEs establish long-term orientated relationships, it is expected that their SCP will be enhanced as a result. However, the part coefficient revealed that SMEs are not inclined to build a long-term relationship with suppliers. This finding is in support of Weiss and Weitz (1992), stating that SMEs reluctance to build a long-term relationship may be as a result of lack of commitment and trust, which might hinder the overall performance of the supply chain. It is also evident that superior SCP is chiefly reliant on the development of RL by SMEs. SMEs must acknowledge that if they are to accomplish and maintain greater SCP, it is important that they establish RL. In support of Wu (2014), it was detected that RL is positively interrelatedwithSCP.

Hypothesis testing 5: The results obtained following the test of Hypothesis 5 confirmed the correlation between DC and SCP. A coefficient of 0.903 was realised after testing Hypothesis 5 . This means that DCs have a strong and positive influence on SCP. Furthermore, the results indicate that the relationship between DC and SCP is significant at $p<001$. From the results, it can be observed that when SMEs capabilities are available in firms, this may lead to supply chain improvement. Once SMEs begin to see a drastic change of new opportunities this will automatically push suppliers to deliver their products and service on time. DCs stress the key role of management to appropriately adjust, integrate and reshape organisational skills and resources as well as internal and external functional competences in order for supply chain to perform (Borch \& Madsen, 2007). SMEs capabilities are said to be dynamic when they provide organisations with the ability to implement different strategies to adopt SCP (Barreto, 2010). The outcomes of the relationship between DC and SCP support the previous studies findings of Tanskanen and Aminoff (2015) and Ladhari (2009). These studies assert that dynamic capability has a significant positive influence on SCP. The findings of the relationship between dynamic capability and service quality lend substantial support to the past research findings of Tee and Pisano (1994) and Das and Tang (2000). These previous studies confirm that DCs have a positive influence on SQ. The relationship between the newly hypothesised RL and DC was found to be positive. Studies on the relationship between SQ and SCP are vast and mostly found good results (Chang 2012; Lawton \& Rajwani 2011). The relationship between DC and RL always has been studied in the literature with contradicting findings. In this study, dynamic capability is found to influence RL positively, which is supported by many scholars such as Chinomona and Pretorius (2011) and Chinomona (2013).

\section{Conclusion}

Contribution and Implication of the Study: This study contributes to organisational (SMEs) research in general and to research on DC, SQ, RL and SCP in several ways. Given the dearth of knowledge on the influence of DC on organisational performance, this study provides important insights into a largely blind spot of SMEs research. Most important, the present study informs SMEs on how DC, SQ and long-term relationships could benefit SCP. In addition, the conceptual model of this study will make a positive contribution to the growing body of knowledge as well as helping SMEs managers and owners to develop strategies that focuses on improving SQ, developing DC as well as measures of RL in order to improve SCP. The findings indicate that the study's theoretical proposition is valid and acceptable. It is also evident that SMEs and their suppliers should devote their efforts towards DC, providing quality service and developing long-term relationships in order to improve or increase SCP. SMEs and their suppliers should recognise that when the relationship between them is good, new changes will appear and service will improve its quality, which will lead to supply chain's improved performance. The results contribute to the understanding of other scholars on why certain firms' supply chains perform better when developing new capabilities, maintaining quality services, establishing and maintaining long-term relationships. Thus, they are more likely to adapt successfully to ever changing business environments. The study further informs managerial practice about the firms' settings in which supply chains are most likely to prosper, thereby providing important information about the preconditions for the development and maintenance of these determinants of SCP. Although SMEs may differ in their ability to develop and apply these determinants and in turn may differ in their ability to adapt to changing environments partly due to their organisational design characteristics. This study has managerial implications for the SME sector. SMEs owners and managers may be able to enhance the levels of SCP by making improvements on DC, improving the quality of their services and cultivating sound and long-lasting relationships with their suppliers. 
This study also contributes to younger generations who are willing to start or own their business in future, as they will be aware of business implementation strategies that can help their business growth. This study will assist SMEs to gain more knowledge on how to build a successful business. The paper both theoretical and practical contribution. This is the first paper to the best knowledge of the researcher that applied the Dynamic Capability View Theory in organisational behaviour literature. Which means the theory added new knowledge to the existing literature on organisational behaviour. The paper has practical contribution to managers or owner of SMEs to practice good management relations to have greater service quality, relationship longevity and good supply chain performance.

Limitations for Future Research: In evaluating the findings of this study, it should be noted that this study is by no means without its limitations. Several limitations of this study are worth discussion. In fact, one of this study's limitations was that the study was confined to only Gauteng province SMEs. Further studies can consider the South African SME sector as a whole. The study employed a quantitative research approach. Future research may consider both a qualitative and quantitative research design using triangulation methodology where a qualitative design could be used in generating rich ideas and explanations. A nonprobability sampling method was undertaken. Since it was difficult to locate an accurate sample frame for the study, convenience sampling was employed to generate an initial sample. Future studies could use other sampling techniques. Another limitation is the fact that the method of data collection relied on accurate introspection of each respondent. Therefore, the responses may be subject to a degree of bias. Despite these limitations, the study advances knowledge regarding SMEs DC, RL, SQ and SCP considering that there is a noticeable absence of prior research within the South African context related to this study. Concerning the drivers of SCP, the findings suggest that SMEs may need to employ a combined strategy aimed at increasing the effectiveness of sensing capability, knowledge capability, reconfiguration resources capabilities and resource integration capabilities in order to enhance the SCP. SMEs can devote valuable corporate resources to SQ and RL to enhance SCP within the sector.

\section{References}

Adams, J. H., Khoja, F. M. \& Kauffman, R. (2012). An empirical study of buyer-supplier relationships within small business organizations. Journal of Small Business Management, 50(1), 20-40.

Augier, M. \& Teece, D.J. (2008). Strategy as evolution with design: the foundation of dynamic capabilities and the role of managers in the economy system. Organization Studies, 29(8-9), 1178-1208.

Barreto, I. (2010). Dynamic capabilities: a review of past research and an agenda for future. Journal of Management, 36(1), 256-280.

Bayraktar, E., Gunasekaran, A., Koh, S. C. L., Tatoglu, E., Demirbag, M. \& Zaim, S. (2010). An efficiencycomparison of supply chain management and information systems practices: a study of Turkish and Bulgarian small and medium sized enterprises in food products and beverages, International Journal of Production Research, 48(2), 425-451.

Borch, 0. J. \& Madsen, E. (2007). Dynamic capabilities facilitating innovative strategies in SMEs.InternationalJournal of Techno Entrepreneurship, 1(1), 109-125.

Branch, A.E. (2009). Global supply chain management and international logistics. Routledge.

Cavusgil, E., Seggie, S. H. \& Talay, M. B. (2007). Dynamic capabilities view: foundations and research agenda. Journal of marketing theory practice, 15(2), 159-166.

Charles, G. (2009). Competitive advantage in small medium-scale enterprises: A resource-based analysis ofTanzanian family and non-family firms. Ph.D. Dissertation: Dar es Salaam. University of Dar es Salaam.

Chang, C. C. (2012). An IPA-embedded model for evaluating creativity curricula. Innovations in Education and Teaching International, 51(1), 59-71.

Chin, T. A., Hamid, A. B. A., Rasli, A. \& Baharun, A. (2012). Adoption of supply chain management in SMEs.Procedia - Social and Behavioral Sciences, 65, 614 -619.

Chinomona, R. \& Pretorious, M. (2011). SME manufacturers' cooperation and Dependency on major dealers. Expert power in Distribution Channels. South Africa Journal of Economics and Management Sciences, 14(2), 170-187. 
Chinomona, R. \& Chinomona, E. (2013). The influence of employees' perceptions of organizational politics onturnover intentions in Zimbabwe's SME sector. Southern African Journal of Business Management, 44(2), 57-66.

Chinomona, R. (2013). Information technology resource as a facilitator of suppliers collaborativecommunication, network governance and relationship longevity in supply chains. Journal of Transport and Supply Chain Managementpages.http://dx.doi.org/10.4102/ jtscm.v7i1.83,

Chinomona, R. (2011). None mediated channel powers and relationship quality: A case of SMES in Zimbabwechannels of distribution. Ph.D. Thesis. Taiwan: National Central University. 1-175.

Chinomona, R., Lin, J., Wang, M. \& Cheng, J. (2010). Soft power and desirable relationship outcomes inZimbabwe distribution channels. African Journal of Business, 11(2), 182-200.

Christensen, R. \& Poufet, P. (2010). Managing 3complexity and changes in SMEs. Journal ofBusiness Research,109(4), 123-126.

Das, T. K. \& Tang, B. S. (2000). A Resource Based Theory of Strategic Alliance. Journal of Management, 26(1), 31-61.

Danneels, E. (2008). Organizational antecedents of second-order competences. StrategicManagement Journal, 29(5), 519-543.

Deshpande, A. (2012). Supply chain Management dimensions, supply chain performance and organizationalperformance: an integrated Framework, International Journal ofBusiness and Management, 7(8), 2-19.

Eshghi, A., Roy, S. K. \& Ganguli, S. (2008). Service quality and customers' satisfaction: An empirical investigation in Indian Mobile Telecommunication service. Marketing Management Journal, 18(2), 119-144.

Fawcett, S. E., Ellram, L. M. \& Ogden, J. A. (2007). Supply chain management: from visionto implementation. Upper Saddle River, N.J: Prentice Hall.

Fink, R. C., Edelman, L. F. \& Hatten, K. J. (2007). Supplier performance improvement in rational exchanges. Journal of Business \& Industrial Marketing, 22(1), 29-40.

Ghylin, K. M., Green, B. D., Drury, C. G. \& Chen, J. (2008). Clarifying the dimensions of four concepts of quality. Theoretical Issues in Ergonomics Science, 9(1), 73-94.

Gunasekaran, A. \& Kobu, B. (2007). Performance measures and metrics in logistics and supply chainmanagement: a review of recent literature (1995-2004) for research and applications. International Journal of Production Research, 45(12), 2819-2840.

Helfat, C. E. \& Peteraf, M. A. (2009). Understanding dynamic capabilities: Progress along a developmental path. Strategic Organization, 7(1), 91-102.

Helfat, C. E. \& Winter, S. G. (2011). Untangling Dynamic and Operational Capabilities: Strategy for the (N) ever-Changing World. Strategic Management Journal, 32, 1243-1250.

Hudson, M. \& Smith, D. (2008). Implementing strategically Aligned Performance Measurement in Small Firms. InternationalJournal of Production Economics, 106 (2), 393-408.

Ihtiyar, A. \& Ahmad, F. S. (2012). Impact of Intercultural Competence on Service Quality and CustomerSatisfaction in the Grocery Retail Industry: A Conceptual Framework. International Journal of Science and Management, 1, 13-27.

Kidder, L. H. (1981). Research Methods in Social Relations. New York, Holt: Rinehart \& Winston.

Kotler, P. \& Keller, K.L. (2010). Marketing Management. 12th ed. USA: Pearson Prentice Hall.

Ladhari, R. (2009). Assessment of the psychometric properties of SERVQUAL in the Canadian banking industry. Journal of Financial Services Marketing, 14(1), 70-82.

Ladhari, R. (2008). Alternative measure of service quality. Journal of managing service quality, 18 (3), 65-68.

Lai, K., Wong, C. W. \& Cheng, T. (2010). Bundling digitized logistics activities and its performance Implications. Industrial Marketing Management, 39(2), 273-286.

Lawton, T. \& Rajwani, T. (2011). Designing lobbying capabilities: managerial choices in unpredictable environments. European Business Review, 23(2), 89- 167.

Mafini, C. \& Omoruyi, O. (2013). Logistics benefits and challenges: the case of SMEs in a South African Local Municipality. Southern African Journal of Entrepreneurship and Small Business Management, 6(166), 145-167. 
Manzouri, M. M., Rahman, M. N. A., Arshad, H. \& Ishmail, A. R. (2010). Barrier of Supply chain managementimplementation in manufacturing companies: a comparison between Iranian and Malaysian companies. Journal of the chines Institute of Industrial Engineers, 27(6), 65-85.

Morgan, A., Neil, Douglas., V. W. \&Mason, H. C. (2009). Market orientation, marketing capabilities, and firm performance. Strategic Management Journal, 30(4), 909-920.

Nunnally, J. C. \& Bernstein, I. H. (1994). Psychometric theory (3rd ed.). New York: McGraw-Hill.

Olawale, F. \& Garwe, D. (2010). Obstacles to the growth of new SMEs in South Africa: A principle component analysis approach. African Journal of Business Management, 4(5), 729-738.

Olugu, E. U. \& Wong, K. Y. (2009). Supply chain performance evaluation: trends and challenges. American Journal of Engineering and Applied Sciences, 2(1), 202-211.

Paiva, E. l., Phonlor, P. \& D'Avila, L.C. (2008). Buyer-Supplier Relationship and Service Performance: an Operations Perspective Analysis. Journal of supply Chain Management,1(2), 77-88.

Pavlou, P. A. \& Elsawy, O.A. (2011). Understanding the exclusive black box of dynamic capabilities. Decision Sciences, 42(1), 239-273.

Prajogo, D. \& Ollhager, J. (2012). Supply chain integration and performance: The effects of longtermrelationship, information technology and sharing, and logistics integration. Production Economics, 135, 514-522.

Sarstedt, M., Ringle, C. M., Smith, D., Reams, R. \& Hair, J. F. JR. (2014). Journal of Family Business Strategy, 5, 105-115.

Shephered, C.\& Gunter, H. (2011). Measuring supply chain performance: Current research and future directions. Behavioral Operations in planning and scheduling. Springer

Supyuenyong, V., Islam, N. \& Kulkarni, U. (2009). Influence of SMEs characteristics on knowledge management processes. Journal of Enterprise Information Management, 22(1/2), 63-80.

Tanskanen, K. \&Aminoff, A. (2015). Buyer and Supplier Attractiveness in a Strategic Relationship: A Dyadic Multiple-Case Study. Industrial Marketing Management, 33(2), 45-60.

Teece, D. \& Pisano, G. (1994). The dynamic capabilities of firms: an introduction. Industrial and Corporate Change, 3(3), 537-556.

Teece, D. J. (2007). Explicating dynamic capabilities: the nature and micro foundations of (sustainable) enterprise performance. Strategic Management Journal, 28 (11), 1319-1350.

Terziovski, M. (2010). Innovation practice and its performance implications in small and medium enterprises in manufacturing sector. A resource based view. Strategic management Journal, 30(31), 892-902.

Thakkar, J., Kanda, A. \& Deshmukh, S. G. (2009). Supply chain management for SMEs: A research introduction. Management Research News, 32(10), 970-993.

Trkman, P., Mccormack, K., De Oliveira, M.P.V. \& Ladeira, M.B. (2010). The impact of business analytics onsupply chain performance. Decision Support Systems, 49, 318-327.

Vitasek, K. (2008). Supply Chain Management Terms and Glossary. An International Journal, 12(2), 153-158.

Weiss, A. M. \& Weitz, E. (1992). Converting from independent to employee Salesforce: The role of perceivedswitching cost. Journal of Marketing Research, 29, 101-105.

Wu, T., Wu, Y. C. Y., Chen, Y. J. \& Goh, M. (2014). Aligning supply chain strategy with corporate environmentalstrategy: a contingency approach. International Journal of Production Economics, 147, 220-229. 